\title{
É o MÉTodo FILOSÓFICO BASEADO NA INTUIÇÃO?
}

\author{
ClÁUdia Ribeiro
}

\begin{abstract}
There is a current and lively debate that opposes naturalistic philosophers to non-naturalistic philosophers about intuition. I start with a critical analysis of that debate, presenting the arguments that naturalistic philosophers make use of in order to debunk the alleged method based on intuitions of non-naturalistic philosophers. Then I introduce the solution that consists in trying to reduce metaphysics to a merely descriptive task, concluding, however, that this move is not satisfactory. I therefore describe 'stylistic' solutions whereby it is argued that the term "intuition" and its derivatives play a rhetorical function in philosophy, or reflect a careless use of vocabulary. Although partly correct, I try to show that they do not eradicate the alleged importance of intuition in philosophy. Finally, I present my own point of view about the issue at hand: in case intuition plays a role in the pursuit of knowledge, be it scientific or philosophical, that role is not methodological, but heuristical.
\end{abstract}

Keywords: Intuition; evidence; rationality; experience.

\section{Introdução}

A intuição é um assunto complexo. A complexidade advém desde logo do facto de o termo ter vindo a ser utilizado, tanto a nível do senso comum como por filósofos e cientistas, em tão variados sentidos que não é exagero dizer que se encontra mergulhado na mais profunda confusão. A única coisa que sabemos bem acerca da intuição é que se trata de uma capacidade cuja descrição é muito difícil. O sentido comum (e etimológico) de 'intuição' como 'visão directa e imediata' não nos esclarece em que consiste essa visão. Como se desencadeia e o que vê ela?

Ora, é este termo nebuloso, 'a intuição', que joga actualmente um papel relevante no interior da filosofia analítica. Desde os anos sessenta do século passado, teve aí lugar um fenómeno que se espalhou como um vírus e cujas consequências, no nosso entender, constituem um verdadeiro infortúnio para a filosofia em geral: a utilização abusiva, infelizmente por parte dos próprios filósofos, do termo 'intuição' ou 'intuitivamente', na sua argumentação.

A associação da filosofia e da metafísica à intuição tem uma história longa e persistente mas não nos vai interessar aqui percorrer essa história. Interessa-nos apenas o modo como o termo 'intuição' é utilizado na filosofia contemporânea. Designa aí, não tanto uma faculdade, mas um tipo de fenómeno mental: algo parece-nos espontaneamente ser verdadeiro (ou falso) sem que saibamos ao certo como chegámos a tal conclusão. A intuição poderá então ser descrita como um tipo especial de crença, uma

Principia 21(3): 411-426 (2017).

Published by NEL — Epistemology and Logic Research Group, Federal University of Santa Catarina (UFSC), Brazil. 
crença em que algo é verdadeiro (ou falso) sem que para tanto possamos apresentar cadeias de argumentos lógicos ou provas de tipo empírico capazes de a justificar.

Mais importante do que uma definição de intuição será perceber qual o seu valor cognitivo. Isto porque, no caso de vários filósofos não-naturalistas (Hales 2000, Zimmerman 2008, Bealer 1996, Jackson 1982, Sosa 2008, Chalmers 2014 ...), a intuição é a própria justificação da crença: é porque foi intuída que a crença se torna legítima. Descrevem as suas premissas como sendo 'intuitivas' ou 'baseadas na intuição' ou que a sua negação é 'contra-intuitiva' e defendem que as intuições são uma via de acesso para o conhecimento não-empírico. Assim, declara Steup:

Vamos dizer que quando se considera a proposição $p$ e se tem uma experiência de se ficar convencido da verdade de $p$, e essa experiência não implica a percepção, a introspecção ou a memória, então tem-se uma experiência puramente intelectual de que $p$ é verdadeira. (1996, p.57)

Ora, que razões temos para confiar nas nossas intuições? São cem por cento fiáveis, revelam-nos a realidade? Ou terão apenas valor indicativo, servindo como guias para posteriores investigações? Ou, pelo contrário, devem suscitar total desconfiança?

O uso reiterado do termo 'intuição' no seio da filosofia analítica foi criando a ideia de que os filósofos (sobretudo os metafísicos), uma vez esgotados os seus argumentos, recorrem à 'intuição'. No caso de uma disputa filosófica ser levada suficientemente longe, chegar-se-á a um ponto em que nada mais estará em causa a não ser um confronto entre intuições acerca das premissas-chave dos argumentos: por exemplo, 'intuitivamente, o mundo exterior existe' e 'intuitivamente, apenas a minha mente existe'. O caso é tão grave que se tornou moeda corrente assumir que as provas dos filósofos se baseiam em 'intuições' e que o método filosófico por excelência é baseado na intuição. Declara, por exemplo, Steven D. Hales: "Qualquer defesa adequada da nossa prática começa com um exame da nossa metodologia, nomeadamente, o apelo à intuição racional”. (2000, p.137). O que distinguiria a metodologia filosófica da metodologia científica seria precisamente o apelo reiterado à intuição da primeira e a confiança que nela depositam os seus praticantes.

É esta pretensa metodologia, o constante recurso à intuição, que se situa no cerne da crítica dos filósofos naturalistas, entre os quais Ladyman e Ross (2007). Como pode alguém levar a sério argumentos filosóficos baseados em intuições? Como pode alguém pretender passar de 'intuitivamente, o mundo exterior existe' para 'a intuição da existência do mundo exterior é verdadeira'? Que tipo de autoridade pode ser atribuído às 'intuições', uma vez que pretendem autojustificar-se e não enfrentam o 'tribunal da experiência'? Ladyman e Ross fazem notar a proveniência duvidosa das premissas dos argumentos 'baseados na intuição', que conduzem à formulação de declarações ontológicas sem consequências observacionais. Embora os cientistas

Principia 21(3): 411-426 (2017). 
considerem a intuição de pouca confiança, os metafísicos não-naturalistas não se coíbem de confiar mais na intuição do que nos 'resultados da ciência'. Daí que, para os filósofos naturalistas, o recurso à intuição seja tomado como prova da inferioridade da metafísica em relação à ciência. As intuições humanas acerca da natureza do universo têm amiúde vindo a revelar-se falsas, não têm valor epistémico, frisam Ladyman e Ross. Como pode então a metafísica não-naturalista pretender pôr questões acerca do mundo? Como pode ter a pretensão de descrever a natureza fundamental da realidade usando tão-só o poder da 'razão pura'? E por que razão seriam as intuições dos metafísicos mais dignas de confiança do que as da restante humanidade?

Ladyman e Ross acrescentam ainda um argumento evolucionista contra a fiabilidade das intuições: estas desenvolveram-se no mundo da média dimensão. Não estão adaptadas nem à macro nem à micro escala. Será pouco plausível que a intuição possa conduzir-nos ao conhecimento de realidades cuja escala difere enormemente daquela a que estamos habituados. E o mais grave é que essas intuições nem sequer podem passar pelo escrutínio científico, estando nós assim condenados a permanecer ignorantes acerca da sua acuidade.

Claro que é possível contra-argumentar que, ao longo da evolução, o homem provavelmente desenvolveu intuições nas quais pode confiar minimamente. A nossa sobrevivência dependeu da nossa boa adaptação ao ambiente. As nossas intuições poderão ter sido produzidas, portanto, por um mecanismo adaptativo. Embora essa adaptação seja limitada no tempo e no espaço, o facto de as intuições humanas terem sido formadas num determinado ambiente e numa determinada época não implica que não possam ser utilizadas frutuosamente num outro ambiente e numa outra época. Com efeito, a mente humana parece ser dotada de admirável plasticidade.

A tese de que a intuição é um produto da nossa evolução afigura-se-nos plausível. No entanto, os mecanismos adaptativos da evolução não merecem a nossa confiança, uma vez que a própria natureza erra amiúde. E apesar de a natureza construir cérebros capazes de a ir compreendendo, de evoluir e de adaptar-se a novos ambientes e não cérebros incapazes de a entender, esses cérebros fazem-no através de tentativas e erros. Geralmente, a natureza tolera os nossos erros e faz com que aprendamos com eles, em vez de com eles nos liquidar. O papel do erro é, pois, fundamental na aprendizagem evolutiva. Podemos, pois, acrescentar que o erro tem-nos ensinado muito mais do que as certezas, certezas essas com que tantos filósofos e cientistas vivem obcecados.

Não que Ladyman e Ross recusem reconhecer a presença da 'intuição' também na ciência. Admitem que muitas vezes se afirma acerca de um bom físico que ele teve uma intuição sólida. Mas acrescentam que, neste caso, o uso da palavra intuição difere, uma vez que se refere "à habilidade bem treinada do praticante experiente de ver num relance como a sua estrutura teórica e abstracta provavelmente - com antecedência em relação a uma verificação cuidadosa essencial — mapeia o espaço de 
um problema”. (Ladyman e Ross 2007, p.15). Um bom exemplo disto seria o caso de Newton e da maçã. Em ciência, a intuição é uma antecipação de resultados prévia à descoberta dos passos e detalhes que conduzem a esses resultados, uma adivinhação de ligações subliminares entre as coisas ou acontecimentos, possível apenas porque existiu uma aprendizagem e treino anteriores relevanates.

Poderá objectar-se que o modo como os cientistas usam a intuição ainda é uma questão em aberto. Talvez não se restrinja ao uso apontado por Ladyman e Ross. O assunto não está suficientemente estudado. Mas a questão é se a intuição é ou não utilizada como prova, além de ser utilizada heuristicamente. Ora, os cientistas parecem não apresentar as suas teorias pedindo que acreditem nelas porque são intuitivas; pelo contrário, justificam-nas através do seu sucesso teórico-empírico. Newton viu num relance a resolução do seu problema (o que só foi possível devido a aturado estudo e reflexão prévios), e depois submeteu a sua 'intuição' à verificação. Ou seja, os cientistas não usam a intuição como prova. Esta é a grande razão pela qual os filósofos naturalistas toleram a presença da intuição na ciência mas não na filosofia. Para Ladyman e Ross, como para muitos críticos empiristas e naturalistas da metafísica não-naturalista (e da filosofia em geral), o problema com as 'intuições racionais' é não serem sujeitas a verificação empírica. Intuições acerca de mundos possíveis, do ser enquanto ser, etc., são inverificáveis. Não podem ser cientificamente testadas, ou seja, a sua correcção parece não poder ser avaliada.

\section{Intuições racionais}

Steven D. Hales (2000) contrapõe à 'intuição empírica' a 'intuição racional'. A 'intuição empírica' remete para factos empíricos do mundo natural e tem estado muitas vezes errada: o universo, lembra Hales, parece-nos 'intuitivamente' newtoniano e não relativista; explica-se 'intuitivamente' melhor o movimento aparente do sol no céu do que pondo a hipótese de que, na realidade, se move relativamente a uma Terra estável.

Vamos deter-nos aqui porque se trata de um bom exemplo para mostrar que o uso do termo 'intuição' e 'intuitivamente', na filosofia analítica é, quanto a nós, bizarro. Cremos que o universo nos parece newtoniano, não 'intuitivamente', mas porque nos baseamos na observação do senso comum, o que não sucede com a hipótese relativista. A explicação ptolemaica e aristotélica do movimento aparente do sol baseavase, também ela, não na intuição mas na observação. O grande problema da física aristotélica era, precisamente, basear-se na observação. O que Copérnico fez foi ousar ir contra a observação; é isso em grande parte que caracteriza a ciência a partir de então. Não há qualquer necessidade de referir a intuição. Aliás, a ter algum papel, a intuição talvez esteja mais em jogo quando se constroem hipóteses que vão

Principia 21(3): 411-426 (2017). 
contra a observação do que quando nos baseamos na observação. É por isto que afirmamos que o uso do termo 'intuição' e 'intuitivamente' nos parece bizarro. O termo 'ingenuidade' e 'ingenuamente' seria mais apropriado.

O que nos salva destas 'intuições' erradas acerca de factos empíricos, prossegue Hales, é a ciência e o 'tribunal da experiência', no qual a sua falsidade é demonstrada.

Mas, quanto a nós, há aqui que objectar que não é tido em conta o facto de o 'tribunal da experiência' raramente ser imparcial, além de ter uma carga teórica considerável. Não existe algo como 'a experiência pura' por contraponto à 'razão pura' de onde provêm as 'intuições racionais'. Regressaremos a esta questão no último ponto deste artigo.

Hales sustém que a intuição da filosofia é racional, não é empírica (2000, p.135). É no tipo de intuição proveniente ‘da pura luz da razão' que se apoia a filosofia (2000, p.135). Ora, nós julgávamos há muito banida a crença numa 'pura luz da razão'. Além disso, é preciso estar atento a este uso ambíguo do termo 'racional'. Racional, no sentido utilizado por Hales, opõe-se a 'empírico' e não a 'irracional'. 'Racional' significa que "provém apenas da razão". 'Intuição racional' é um termo utilizado pelos filósofos não-naturalistas para designar então a 'razão pura', o 'raciocínio a priori' independente da investigação empírica, da experiência a posteriori.

Nesta ordem de ideias, as intuições empíricas não seriam, portanto, irracionais; pelo contrário, o facto de serem empíricas parece acrescentar-lhes racionalidade. Para estes autores, o problema reside apenas nas intuições 'racionais' (provenientes apenas da 'razão pura'), precisamente por não serem empíricas.

Hales define 'intuição racional' como um método a priori de adquirir juízos e crenças justificadas: “Ter uma intuição de que $A$ é parecer-nos que $A$ é necessariamente verdadeira." (2000, p.137). E fornece vários exemplos. Os objectos da intuição são necessidades lógicas, proposições do tipo "Se $p$ é verdadeira e $q$ é verdadeira, então $p \& q$ é verdadeira"; se $p$ é mais alto do que $q$ e $q$ é mais alto do que $r$, então $p$ é mais alto do que $r$; ou o princípio de não contradição de Aristóteles.

Mais uma vez, continua a espantar-nos esta utilização do termo 'intuição'. Parecenos completamente inútil introduzi-lo neste tipo de casos. É a razão que nos diz que assim é, e isto no caso de se tratar de apenas uma única faculdade a estar em jogo e não de mais do que uma. Nada disto implica, obviamente, que as crenças assim geradas estejam correctas. Não há fontes de conhecimento certo: nem a razão, nem a observação, nem a percepção, nem a intuição têm sempre razão, antes erram amiúde. Mas é precisamente por errarem que o homem desenvolve mecanismos de auto-correcção, um dos quais é a experimentação científica.

Um outro exemplo de Hales:

Por que razão estamos nós convencidos de que torturar bebés por prazer está errado? Ou porque nos parece intuitivamente imoral, ou porque não se enquadra nos princípios morais mais gerais que acreditamos ser intuitivamente

Principia 21(3): 411-426 (2017). 
plausíveis. Sem apelar à intuição é difícil ver como poderíamos sequer começar a discutir questões acerca de o compatibilismo ser uma noção adequada de liberdade, ou o que constitui um comportamento virtuoso ou se as partes são essenciais para o todo (...) (2000, p.137)

Concordamos que seja plausível que, intuitivamente, estejamos convencidos de que torturar bebés por prazer está errado. 'Intuitivamente' no sentido em que, sem quase pensar no assunto, acreditamos que o seu contrário não pode estar correcto. Em filosofia, porém, exige-se 're-flexão', tornar a pensar, exige-se que não se permaneça neste nível da intuição do senso comum e se apresente exigentes cadeias sistemáticas de razões que demonstrem que é errado torturar bebés por prazer; ou até que é correcto torturar bebés por prazer (uma vez que a filosofia não tem de se submeter ao senso comum, antes amiúde o contradiz). O mesmo se passa em relação às partes serem essenciais (ou não) para o todo, ou aquilo que constitui um comportamento virtuoso, etc.

O termo intuição é ainda utilizado na filosofia contemporânea para designar a proveniência das proposições dos filósofos não-naturalistas acerca de tropos, universais, mundos possíveis, composição mereológica, etc. Estas intuições, ditas hoje 'racionais' (provenientes da 'pura luz da razão') coincidem, portanto, e em larga medida, com as 'intuições não-racionais' de Rudolf Carnap: "Outros filósofos usam o nome "metafísica" para o resultado de um processo não-racional, puramente intuitivo; este parece ser o uso mais apropriado. (...) Ao referirmos a metafísica como uma área não-racional, estamos de acordo com muitos metafísicos". (1928, p.295)

Em Überwindung, Carnap afirma que as metafísicas pós-kantianas pretendiam fazer-nos crer que, pela intuição, pelos dados imediatos da consciência, é possível aceder à natureza íntima das coisas que transcende aquilo que é fundado empiricamente, como a 'durée', as Essências, as Coisas em Si, o Absoluto. A metafísica seria, pois, resultado, não de processos racionais, mas de uma intuição não-racional e teria como objecto 'o inefável'. Palavras como durée, Essências, Coisas em Si e Absoluto não chegam a ser conceitos; são indefiníveis. Não é possível conceber experiências acerca da durée, de Essências, Coisas em Si e Absoluto que torne possível uma sua definição. Estão fora do sistema espácio-temporal do mundo físico, não podendo haver delas, por isso, nenhuma verificação. Ora, todo o conhecimento é comunicável, contrapunham os positivistas. De onde se seguia que a metafísica como conhecimento é impossível. Não pode haver conhecimento daquilo de que o metafísico tem intuição. É esta razão pela qual as intuições são descritas como 'não-racionais'.

\section{Metafísica prescritiva?}

Recordemos que o verdadeiro problema está em que muitos metafísicos não-naturalistas consideram que a intuição é uma prova a favor da verdade. Grande parte deles vê

Principia 21(3): 411-426 (2017). 
a intuição como um método a priori de aquisição de crenças justificadas. E fazem-no sugerindo que uma boa razão para acreditar em $p$ é o facto de se intuir que $p$. Logo, uma vez que a metafísica não-naturalista recorre abundantemente à intuição, no caso de se considerar que a intuição não pode constituir-se como uma prova a favor da verdade, então uma parte substancial da prática filosófica não está justificada.

Se considerarmos que a filosofia diz respeito ao mundo exterior e não só aos nossos esquemas conceptuais, que tipo de confiança podemos ter em intuições acerca do mundo exterior? Mais, como podemos considerar que são guias para verdades respeitantes a esse mundo exterior? Que relação existe entre as intuições humanas e o mundo exterior? Como não se avançou com uma explicação cabal dessa relação, é natural que as intuições levantem as maiores suspeitas. Filosoficamente, "intuir que $p$ " é uma experiência pessoal consciente à qual só aquele que a experiencia tem acesso. Não é claro que seja, de algum modo, acessível aos outros, embora Frank Jackson defenda que "nós, [os filósofos] sabemos que o nosso caso é típico e portanto podemos generalizar a partir dele" (1998, p.37). No entanto, Jackson enreda-se aqui num círculo vicioso porque aquele "sabemos" parece provir igualmente de uma intuição.

Por enquanto, não existe uma explicação científica do funcionamento da intuição e de como se relaciona de forma fiável com o mundo exterior. No caso das percepções, nas quais muitas crenças se baseiam e que também são privadas, sucede o contrário. Sabemos como as percepções se relacionam com o seu objecto. Mas não sabemos como as intuições o fazem. Uma solução possível para este problema é considerar que a metafísica deve ser descritiva (Goldman 1992 e, mais recentemente, por exemplo, Benovsky 2013). Benovsky (2013) reconhece que a ciência (física, psicologia experimental, a ciência cognitiva) pode ser útil para avaliar algumas teorias metafísicas, as mais próximas da investigação empírica. Mas não pode ser útil para avaliar aquelas que estão muito distantes de uma base empírica, isto é, aquelas que se baseiam na "intuição" (referentes a tropos, universais, composição mereológica, etc.). Benovsky centra-se neste último caso. Reconhece que existem bastantes teorias metafísicas que são contra-intuitivas, mas acredita que muitas teorias intuitivas se baseiam na nossa experiência fenoménica e contingente diária. Insiste, quanto a nós com razão, que a metafísica não se afasta de todos os tipos de experiência, não é um produto de uma "razão pura" ou de "especulação de poltrona". O problema é que, a partir da mesma experiência fenomenológica, teorias metafísicas concorrentes podem surgir quando a nossa experiência do mundo é neutra em relação a ambas. Por exemplo, a partir da visão de uma maçã a mudar ao longo do tempo, de vermelha e suculenta a tornar-se castanha e podre, podemos abraçar tanto o Endurantismo como o Perdurantismo. A nossa experiência do mundo não decide a favor de um ou de outro. Portanto, acautela Benovsky, devemos ser extremamente cuidadosos ao apelar para este tipo de "intuições" ao fazer metafísica, porque elas são, na maioria das vezes, enganosas e ilusórias. A sua proposta final é apoiar uma espécie de anti-realismo em 
que a metafísica é entendida como a investigação do mundo como ele nos é dado (diz-nos que os nossos conceitos são semelhantes) e não como o mundo é.

Esta metafísica anti-realista de Benovsky aproxima-se grandemente da metafísica descritiva de P. F. Strawson. Strawson (1959) designou por 'metafísica descritiva' aquela que visa descrever tão-só os nossos esquemas conceptuais, para tanto agindo como se a estrutura da realidade neles se espelhasse. A metafísica descritiva descreve e busca as razões das nossas crenças instintivas, por exemplo, a crença de que há um mundo que contém coisas, algumas das quais são independentes de nós. Consagrase às características gerais, sobretudo aos pressupostos existenciais dos esquemas conceptuais que usamos habitualmente, porque se considera que existe um acesso privilegiado aos nossos estados mentais.

Todavia, é possível pôr em causa a viabilidade epistemológica da metafísica descritiva. Inscreve-se na cisão kantiana entre, por um lado, o homem e as suas representações mentais e, por outro, a realidade, o mundo e a natureza, como se os primeiros fossem independentes dos últimos. Ora, podemos pôr em causa o interesse que os nossos conceitos têm se forem realmente independentes do que as coisas são, se nada dizem acerca daquilo de que são conceitos e que lhes é exterior. Podemos ainda optar por reconhecer que tanto a actividade quanto os produtos do pensamento humano são parte integrante da realidade por ele pensada. Contra a ideia de que é possível conhecer as estruturas do nosso pensamento mas não é possível saber nada acerca do mundo exterior no qual se desenvolveram todos os nossos sentidos, assim como a nossa mente, contraporemos: por que haveria a mente humana de ser a única parte inteligível do universo, a única coisa que pode ser conhecida? E, para manter a coerência, a linha de pensamento descritiva não deveria estender o cepticismo em relação ao conhecimento do 'mundo exterior' até ao cepticismo em relação ao 'mundo interior'?

A metafísica revisionista ou prescritiva pretende mudar a estrutura do nosso pensamento para melhor, o que parece indicar a introdução do factor 'realidade': uma melhor estrutura é aquela que apresenta uma melhor imagem da realidade, a sua verdadeira estrutura. De acordo com esta perspectiva, a metafísica é uma tarefa crítica, não de mera descrição de conceitos, mas de revisão desses conceitos. Ora, é contra o plano de fundo da realidade que os conceitos são revistos, criticados e refinados. Só assim podem tornar-se mais verdadeiros. A metafísica revisionista é a única que merece por inteiro o nome de metafísica, uma vez que afasta a ideia bizarra de que entre homens e mundo existe uma espécie de barreira intransponível que acaba por conduzir ao cepticismo e ao relativismo. Veicula um realismo no qual o mundo é independente da mente humana mas no qual essa mente — com a sua linguagem e com a sua lógica - é parte desse mundo. Sendo parte do mundo, não nos parece impossível mas, pelo contrário, uma necessidade, que a mente seja capaz de o ir conhecendo, embora o faça tacteando e errando, mas sempre aprendendo.

Principia 21(3): 411-426 (2017). 


\section{Outras propostas de solução}

Em face de tal panorama, não é de admirar que muitos filósofos se inquietem com esta nova imagem da sua disciplina, incertos como estamos todos do que seja exactamente a 'intuição' e do grau de confiança que ela merece. Esta imagem foi, infelizmente, criada pelos seus próprios praticantes, o que contribui em muito para a descrição da filosofia como uma actividade de poltrona (armchair activity), de mera análise de conceitos, apartada de toda e qualquer experiência.

A argumentação contra a imagem da filosofia que se baseia na intuição e se serve dessa intuição como prova de verdade parece-nos, além disso, muitas vezes frouxa. Erlenbaugh e Molineaux (2009), por exemplo, insurgiram-se contra essa imagem, afirmando que é desnecessária para explicar o papel da intuição na argumentação filosófica. Se a investigação filosófica se preocupa sobretudo com factos e entidades que não são mentais - e Erlenbaugh e Molineaux assim o crêem — então a intuição não pode desempenhar um papel de prova. E concluem, com basta razão, que "se os filósofos que se ocupam dessas tarefas têm estado a utilizar as intuições como provas, como muitos declaram, então têm estado ocupados num empreendimento desastrosamente mal-concebido". (2009, p.36). Não obstante, uma vez que muitos filósofos afirmam recorrer à intuição, a conclusão de Erlenbaugh e Molineaux é a de que esses filósofos se enganaram quanto ao papel desempenhado por ela. O papel relevante da intuição em filosofia não é o de uma prova, mas antes um papel heurístico e retórico. A intuição, que é para ambos tão-só uma inclinação para acreditar, pode tornar um argumento persuasivo; mas não o torna uma boa justificação das suas conclusões. Quando uma audiência partilha da mesma intuição (da mesma inclinação para acreditar) que o seu autor, a argumentação deste é bem sucedida, é persuasiva. Ou seja, para Erlenbaugh e Molineaux, a intuição desempenha "um papel puramente heurístico e retórico para sustentar posições filosóficas, ajudando a promover modelos da realidade mais simples e mais psicologicamente apelativos". (2009, p.3).

A nós, todavia, parece-nos que Earlenbaugh e Molineaux não chegam a insurgirse contra a imagem da filosofia na qual a intuição pretensamente desempenha um papel importante, que é o que tencionamos fazer. E isso porque é tão empobrecedor dar como razão da adopção de $p$ 'porque intuo p' como 'porque estou inclinado a acreditar em $p$ '. Ambas as razões podem ser aceites na conversação diária, mas não se adequam a um nível filosófico. No fim de contas, filósofos são aqueles que se esforçam precisamente por oferecer argumentos a favor ou contra $p$. São aqueles que oferecem uma argumentação sustentada para as suas crenças. Quando se dá como razão 'porque intuo p' ou 'porque estou inclinado a acreditar em p' não se está ainda no nível reflexivo.

Cien Dorr e Herman Cappelen oferecem ainda uma outra caracterização do papel desempenhado pela intuição em filosofia. De acordo com Dorr (2010) , o apelo

Principia 21(3): 411-426 (2017). 
à intuição não faz parte de uma estratégia de argumentação. Trata-se tão-só de um recurso estilístico para indicar que se toma uma determinada proposição como premissa sem que se deseje apresentar argumentos para tanto. Equivale a um 'parece-me que', mostra que não se vai continuar a justificar uma afirmação. Logo, advoga Dorr, não há que criticar essa metodologia mais do que se critica a metodologia de apresentação de argumentos apoiados em premissas.

Revoltado com a descrição corrente da sua disciplina, Herman Cappelen vai ao encontro de Dorr em Philosophy Without Intuitions (2012) e, mais recentemente ainda, em X-Phi Without Intuitions (2014). Através da análise linguística e textual de excertos filosóficos, infelizmente numerosos, onde tem surgido o termo 'intuição' e seus derivados, Cappelen critica a tese metafilosófica a que chama 'Centralidade': os filósofos analíticos contemporâneos confiam em intuições como provas para teorias filosóficas. Mas a 'Centralidade', diz Cappelen, é falsa. Aqueles filósofos têm crenças erradas acerca dos próprios métodos que utilizam. Desde logo, frisa, não há nenhum uso teórico dominante do termo 'intuição' entre os filósofos 'analíticos', imperando antes o desacordo quanto à sua definição. Além disso, cada escola e corrente parece utilizá-lo de maneira única. Uns defendem que a intuição deve ser baseada apenas na competência conceptual, outros não; uns pensam que as intuições são intuições de verdades necessárias, outros não; uns acreditam que a intuição implica uma fenomenologia especial, outros não, etc.

Cappelen nomeia três estratégias principais para compreender a 'conversa sobre intuição' ('intuition' talk). Primeiro, que se remova simplesmente o termo 'intuição' ou 'intuitivo' e afins sem influenciar a substância do argumento. Dado que a maioria das vezes se pode remover sem prejuízo a referência à intuição, então isso significa que ela não é invocada como prova (Cappelen 2012, pp.63-64). Segundo, a referência à intuição serve muitas vezes apenas para descrever afirmações obtidas com pouca reflexão, esforço e raciocínio (Cappelen 2012, pp.65-68), o que vai de encontro à nossa própria suspeita. Terceiro, a referência à intuição indica amiúde que as proposições intuitivas são aquelas que fazem parte da base pré-teórica comum. $\mathrm{O}$ que se quer dizer é que p é uma proposição que ou pode ser justificada ou já o foi, sem que seja tomada uma posição acerca do assunto em questão. Ora, o facto de uma proposição ser pré-teórica em nada informa sobre o seu modo de justificação (Cappelen 2012, pp.68-71).

No que diz respeito à questão de os filósofos elaborarem experiências mentais no decurso dos seus argumentos cuja intenção é veicular determinadas intuições de modo a servirem de prova para uma certa tese ou princípio, Cappelen prossegue na mesma direcção: analisa várias dessas experiências e conclui que, também neste caso, não assentam, na verdade, em intuições. O que sucede é o oposto: os filósofos estão interessados nas razões por detrás das respostas dadas. Por que razão estão as pessoas convencidas de que essas respostas são correctas? Portanto, os filósofos não

Principia 21(3): 411-426 (2017). 
confiam em intuições: se não são justificadas através de razões e argumentos, então as respostas, por si só, são consideradas sem interesse. O que a filosofia faz é apresentar razões e argumentar e ainda detectar nos argumentos precisamente aquelas crenças ou juízos que não foram devidamente justificados e a que muitos chamam erradamente 'intuições' (Cappelen 2012, cap.8). Logo,

\begin{abstract}
Vale a pena acentuar que, de acordo com este diagnóstico, a utilização [do termo 'intuição' e derivados] não é motivada (nem se ancora) por nenhumas tomadas de posição ou pontos de vista realmente filosóficos acerca de intuições ou da metodologia filosófica — é nada mais do que um tique verbal sem nenhum fundamento filosófico (Cappelen 2012, p.22).
\end{abstract}

Suspeitamos que Cappelen tem razão, em grande parte, quando denuncia tratarse de preguiça mental e de uso irresponsável de vocabulário. É, portanto, lamentável que os filósofos tenham vindo a fazer uma má escolha do termo a utilizar, quando o mínimo que se exige deles é um emprego cuidado da linguagem. Parece, de facto, que algo vai mal no reino da filosofia analítica.

Não obstante, como apontam Mclaurin e Dyke, há outro problema: as análises de tipo Lewisiano que parecem contradizer o que defendem Dorr e Capellen (Mclaurin e Dyke 2011, p.296). As análises de tipo Lewisiano, praticadas, entre outros, por Krieger, Sider, Zimmerman e Markosian, propõem que teorias rivais sejam avaliadas de acordo com um certo número de virtudes teóricas. Entre essas virtudes teóricas (elegância, parcimónia, poder explicativo, acordo com as teorias adoptadas em física, etc.) figura a intuição do senso comum. Se uma teoria é especialmente intuitiva ou conforme ao senso comum, isso joga a favor dela; se for especialmente contraintuitiva, isso joga a seu desfavor. Ou seja, a intuição parece ter, de facto, um papel de prova.

Apesar disso, e antes de mais, é de lamentar que os naturalistas que criticam a metodologia baseada na intuição tomem a parte pelo todo, isto é, que tomem as análises Lewisianas, apenas uma parte da metafísica e filosofia actual, como se representassem o seu todo.

\title{
5. Um falso problema
}

É, pois, um erro nefando considerar que intuições podem ser consideradas provas. A existirem, servem apenas para serem criticadas e, se possível, testadas empiricamente. A prática filosófica não se baseia em intuições. Quem gostaria de fazer parte de uma actividade que se baseia em intuições? A putativa fonte de uma teoria filosófica não deve ser confundida com o seu método.

Regressando a Hales, este acaba por declarar:

Principia 21(3): 411-426 (2017). 
Pensamos que a intuição como um método de determinação da verdade de proposições a priori é epistemicamente preferível a confiar na leitura de mãos, bolas de cristal e cartas de Tarot. No entanto, se não tivermos justificação para a crença de que a intuição justifica alguma coisa, é difícil ver por que razão é melhor do que o oculto. Se dois métodos para descobrir a verdade não têm valor, é demasiado difícil perceber qual deles é o pior. (Hales 2000, p.143)

O que acontece é que, ao contrário do que Hales pretende demonstrar, a intuição não justifica nada; logo, não é melhor nem pior do que o oculto. E, possivelmente, estará mais em jogo na leitura de mãos, nas bolas de cristal e nas cartas de Tarot do que em filosofia. Mas a grande diferença está em que, em filosofia, as hipóteses levantadas, sejam elas provenientes de uma intuição, da observação, da razão, etc., têm de ser racionalmente criticadas e sustentadas ou rejeitadas através de cadeias sistemáticas de argumentos. No ocultismo, isso é dispensado. Não é possível discutir racionalmente intuições ocultistas, uma vez que no ocultismo se pede que produtos de uma 'intuição' ou 'revelação' súbita sejam aceites sem mais delongas. O ocultismo não é, por isso, considerado verdadeiro conhecimento, mas antes uma actividade irracional. Avesso à crítica, apresenta mecanismos de defesa que fazem uso da autocontradição.

Pelo contrário, o que está sobretudo em jogo em filosofia, tal como o que está em jogo na ciência, é a razão, "instrumento dos instrumentos", como a descrevia Leibniz, no sentido em que existe abertura à crítica. Todas as putativas verdades filosóficas, como todas as putativas verdades científicas, devem ser questionadas. Portanto, a filosofia, a ter um único método, será o método crítico, racional, no qual a arquitectura dos argumentos é submetida a um escrutínio crítico e obedece a um critério de clareza; não se trata de todo de um método baseado na intuição, caso esse método seja tido como conducente à verdade.

Mas de novo se ergue, pois, o velho problema da escolha entre teorias filosóficas rivais: como decidir entre elas se não podem enfrentar o 'tribunal da experiência'?

Em primeiro lugar, comecemos por lembrar que as próprias teorias científicas são subdeterminadas pelas provas empíricas. As teorias científicas não são totalmente verificadas ou corroboradas pela experiência empírica, ou não seriam teorias. Todas as teorias são-no, precisamente, por tentarem ver para lá do que é empiricamente dado. Além disso, não existem provas empíricas 'puras', dado que as provas empíricas que decidiriam a escolha estão carregadas de teoria. O conhecimento científico forma um conjunto que não só é teoricamente informado como tem conteúdo empírico. Este não pode ser abstraído do conjunto.

Como muitos filósofos da ciência têm vindo a alertar, no séc. XX com Collingwood (1940), Popper (1974), Kuhn (1962), Agassi (1964), etc., e no séc. XXI com, por exemplo, Chakravartty (2007) ou Zahar (2007), embora o grau de proporção de acti- 
vidade empírica e teórica varie entre as ciências, nenhuma delas é levada a cabo sem teoria, mais exactamente, sem teses filosóficas. A filosofia, sobretudo a metafísica, está presente em todas as fases da actividade científica. São pressupostos filosóficos e metafísicos que abrem caminho à formulação de hipóteses científicas a ser testadas empiricamente, à acção concreta do cientista no interior do seu programa. São eles que, numa dada época, delimitam o tipo de objectos existente no mundo e estipulam a natureza de uma prova empírica fiável, os objectivos a alcançar e os problemas a resolver, assim como as perguntas e respostas consideradas aceitáveis.

Em segundo lugar, se não podemos provar que uma teoria filosófica é verdadeira podemos, no entanto, escolher racionalmente entre teorias filosóficas rivais. Como defende Popper, as teorias filosóficas ou científicas integram-se numa cadeia de problemas que tentam resolver. Portanto, podem ser discutidas racionalmente tendo em conta esses mesmos problemas. Essas discussões consistem na avaliação crítica da qualidade da solução apresentada; em descobrir se a solução é superior às que são apresentadas por outras teorias; se é inspiradora e frutuosa; se tem capacidade de sugerir novos problemas e novas soluções; e, por fim, se poderá ou não ser testada empiricamente. No caso de uma teoria científica, a resposta a esta última questão será positiva. No caso de se tratar de uma teoria filosófica, a resposta à mesma questão será negativa. Todas as outras, porém, podem ser-lhe aplicadas. (Popper 1982, pp.198-201).

Com efeito, a história da ciência mostra que, no contexto da metafísica mais próxima do reino empírico, este tipo de escolha racional tem estado em jogo. Várias teorias filosóficas têm sido abandonadas por se revelarem demasiado difíceis de sustentar, acabando por ser preteridas em relação a outras. A teoria dos 'turbilhões' de Descartes foi preterida em favor da filosofia atomista que se revelou muito mais manejável e fértil ao ser transferida para o idioma da ciência. De modo análogo, as filosofias do universo uno, sem geração e sem corrupção (defendidas pelos antigos gregos, Descartes, Leibniz, Espinoza), foram preteridas em favor de teorias do universo como um sistema evolutivo e corruptível.

Se analisadas em profundidade e não forem desmembradas em proposições isoladas, tendo-se antes em conta o seu contexto, mesmo as teorias metafísicas mais afastadas do reino empírico, além de ser possível avaliá-las racionalmente, são relevantes para a ciência. Questões acerca de eventos, ou do que é uma parte e se o todo é igual à soma das partes, ou acerca de mundos possíveis (aliás, ideia análoga ocorreu a um físico, Hugh Everet III: a interpretação de multimundos da mecânica quântica), etc. são muito interessantes para a ciência.

Claro, não há como iludir o facto de que a ciência, além da crítica, tem ainda a experimentação para avaliar a solidez das suas teorias. É esta testabilidade, este controle empírico das teorias, que está na génese da aura de fiabilidade de que a ciência goza. Quando certas teorias passam com sucesso por vários testes severos, 
talvez haja boas razões para as aceitar. Mas daí a inferir-se que essas teorias são verdadeiras e que as teorias que não foram submetidas a testes empíricos não têm valor é um passo que é necessário recusar. Esta recusa parece-nos louvável pois, embora seja compreensível que se confie mais em teorias que foram testadas, é preciso ter em conta, repetimos, que as teorias científicas têm partes não testáveis e que 'ser testável’ é um factor contingente, histórico. Conceber uma teoria testável significa tão-só conceber uma teoria testável na época em que é concebida. O teste empírico não consegue decidir que a teoria é verdadeira. Consegue apenas decidir que, em princípio, é falsa ou que a falsidade não foi comprovada.

Como consequência, e apesar da sua ligação às provas empíricas, a associação directa da ciência à verdade e mesmo à falsidade é problemática. Assim, se a impossibilidade de conhecer com certeza o valor de verdade das teorias filosóficas é um problema, o certo é que o 'tribunal da experiência', tantas vezes invocado para decidir o valor das teorias científicas, também é um problema. As provas empíricas não são, como pensam os empiristas estritos, uma garantia inequívoca e uma fonte de autoridade.

Deste modo, a questão não é saber de imediato se as teorias metafísicas e filosóficas são falsas ou verdadeiras. A questão é investigar se e como podem contribuir para a busca da verdade. A contribuição para a busca da verdade oferecida pela teoria dos turbilhões veio a ser muito inferior à da teoria atomista.

O debate em torno da intuição de alguma filosofia analítica actual deriva, portanto, de o problema estar mal posto. Os seus intervenientes partem de vários pressupostos que urge pôr em causa, como uma distinção rígida entre a priori e a posteriori; a metafísica lidaria com o a priori e a ciência com o a posteriori; e a crença num conhecimento fidedigno (a posteriori) e num pretenso conhecimento (a priori); por fim, enferma daquilo a que se poderá chamar 'a doença da certeza'.

Ciência e filosofia estão justificadas epistemologicamente, embora só consigam alcançar verdades provisórias. Ambas partem, não de intuições, mas de problemas; no intuito de os solucionar, levantam-se hipóteses que poderão ocasionalmente ser sugeridas por intuições, por observações, pela razão - mas nenhuma pode ser tomada como prova e todas devem ser submetidas a críticas severas que avaliem o seu poder explicativo e a sua resistência. Nem a intuição, nem os sentidos, nem a razão são guias fiáveis para a descoberta da realidade. Se a intuição, de facto, desempenha um papel relevante no conhecimento, tanto em ciência como em filosofia esse papel será heurístico e em nenhum caso dogmático.

\section{Agradecimentos}

Desejo expressar o meu agradecimento aos três revisores providenciados pela Revista Principia pelos comentários e sugestões que ajudaram a melhorar este meu artigo.

Principia 21(3): 411-426 (2017). 


\section{Referências}

Agassi, J. 1964. The Nature of Scientific Problems and Their Roots in Metaphysics. In: M. Bunge (ed.) The Critical Approach to Science and Philosophy, pp. 189-211. London: The Free Press of Glencoe Collier-McMillan Limited.

Bealer, G. 1996. On the possibility of philosophical knowledge. Philosophical Perspectives 10: $1-34$.

Benovsky, J. 2013. From Experience to Metaphysics: On Experience-based Intuitions and their Role in Metaphysics. Noûs 47(3): 1-14.

Cappelen, H. 2012. Philosophy Without Intuitions. Oxford: Oxford University Press.

—. 2014. X-Phi Without Intuitions. In: A. Booth; D. P. Rowbottom (eds.) Intuitions. Oxford: Oxford University Press.

Carnap, R. 1928[1967]. Der Logische Aufbau der Welt. Tradução inglesa: The Logical Structure of the World. Pseudoproblems of Philosophy. London: Routledge and Kegan Paul (1967).

- 1932. Überwindung der Metaphysik durch logische Analyse der Sprache. Erkenntnis 2(4): 219-241. Tradução inglesa: The Elimination of Metaphysics Through Logical Analysis. In: A. Ayer (ed.) Logical Positivism, pp.60-81. Glencoe IL: The Free Press (1959).

Chakravartty, A. 2007. Six Degrees of Speculation: Metaphysics in Empirical Contexts. In: B. Monton (ed.) Images of Empiricism: Essays on Science and Stances, with a Reply from Bas C. van Fraassen, pp.183-208. Oxford University Press.

Chalmers, D. 2014. Intuitions in philosophy: a minimal defense. Philosophical Studies 171(3): 535-544.

Collingwood, R. G. 1940[2002]. An Essay on Metaphysics. Oxford: Clarendon Press.

Dorr, C. 2010. Review of Ladyman and Ross, Every Thing Must Go. Notre Dame Philosophical Reviews. http://ndpr.nd.edu/review.cfm?id=19947 (acedido a 27-03-2015)

Erlenbaugh, J.; Molineaux, B. 2009. If Intuitions Must Be Evidential than Philosophy is in Big Trouble. Studia Philosophica Estonica: 35-53.

Goldman, A. 1992. Cognition and modal metaphysics. In: Liasions: Philosophy Meets the Cognitive and Social Sciences, pp.216-236. Cambridge, MA: The MIT Press.

Hales, S. D. 2000. The Problem of Intuition. American Philosophical Quarterly 37(2): 135147.

Jackson, F. 1982. Epiphenomenal Qualia. Philosophical Quarterly 32: 127-136.

- 1998. From Metaphysics to Ethics: A Defense of Conceptual Analysis. New York: Oxford University Press.

Kuhn, T. 1962. The Structure of Scientific Revolutions. Foundations of Unity of Science. Edição brasileira: A Estrutura das Revoluções Científicas. São Paulo: Perspectiva, 2007.

Ladyman, J.; Ross, D. 2007. Everything Must Go: Metaphysics Naturalized. Oxford: Clarendon Press.

Mclaurin, J.; Dyke, H. 2011. What is Analytic Philosophy For? Australasian Journal of Philosophy 90: 291-306.

Popper, K. 1982[1992]. Metaphysical Epilogue. In: Quantum Theory and the Schism of Physics, pp.159-211. Cambridge: Routledge.

- 1974[1985]. The Problem of Demarcation. In: D. Miller (ed.) Popper Selections. New Jersey: Princeton University Press.

Principia 21(3): 411-426 (2017). 
Sosa, E. 2008. A Defense of the Use of Intuitions in Philosophy. In M. Bishop; D. Murphy (eds) Stich and His Critics. Oxford-New York: Blackwell.

Strawson, P. F. 1959. Individuals. An Essay in Descriptive Metaphysics. London: Methuen.

Steup, M. 1996. An Introduction to Contemporary Epistemology. NJ: Prentice Hall

Zahar, E. 2007. Why Science Needs Metaphysics: A Plea for Structural Realism. US: Open Court Publishing Co.

Zimmerman, D. 2008. The Privileged Present: Defending an "a-theory" of time. In: T. Sider; J. Hawthorne; D. W. Zimmerman (eds.) Contemporary Debates in Metaphysics, pp.211-225. Blackwell.

CLÁUdiA RIBEIRO

Doutorada em História e Filosofia das Ciências pela Faculdade de Ciências da Universidade de Lisboa.

ryuko@iol.pt 